\title{
Parallel worlds galore
}

\author{
The 50th anniversary of an astonishing scientific hypothesis deserves celebration. So too do the truly \\ astounding tales of a literary genre that anticipated it.
}

rom the evidence of our cover, you could be forgiven for thinking that you are holding a copy of Nature from an alternate universe. And if that were the way your imagination took off, it would be doing just what our cover seeks to do - celebrating the overlap between the world of science and the fables it inspires and feeds on. In particular, the 'Astounding Tale' of a plethora of alternate universes is at the same time a well-worn theme of science fiction and a valid, if speculative, way of understanding the ultimate implications of Schrödinger's wave equation.

The idea of a 'many-worlds' multiverse, introduced into physics 50 years ago this month by Hugh Everett, neatly highlights the intersection between science and science fiction - which is why our coverage of the anniversary spills from our News Features pages into our Books \& Arts pages (see pages 15, 18, 23 and 25). For the most part, though, the two domains are themselves seen as alternates. It is a cliché of science popularization to proclaim that phenomenon X, once science fiction, is now science fact, as though the two were in some way mutually exclusive. This might suggest to some that science fiction is worthless; alternatively, it can tacitly imply that it is the job of science to reify the fancies of science fiction. Neither implication is useful.

The interaction between science and science fiction is more complex and symbiotic. Science fiction feeds on science. It also anticipates it. For good or ill, it articulates possibilities and fears: the notion of the super-weapon was commonplace in science fiction long before the Manhattan Project, and no debate about genetic technology seems complete without an appearance by Victor Frankenstein and his creature. More positively, science fiction provides crucial raw material - the minds of young people who will in time become scientists themselves. Not every science-fiction-reading teenager becomes a scientist, nor do all scientists grow up with shelves of Wells, Asimov and Le Guin by their beds. But the inspirational value is real.

This is not to say that science fiction is a childish thing, to be grown out of. But it does undeniably have a frequently childish character, one that reveals its true nature. Childhood is a time of games; games that allow their players' curiosity free expression while at the same time preparing them for a life in which every year brings novelties both anticipated and unlooked for. Science fiction, too, provides a way of exploring what is to come. Its main aim is not to foretell the future - indeed, the great Ray Bradbury once remarked that he wrote not to predict the future, but to prevent it. Yet even though it can be serious and frightening, it is not at heart a literature of warning, either. It is a literature of playfulness. Within the constraint of telling human stories about more-or-less human beings, it revels in "Science fiction does not tell us what the future will bring, but helps us to understand what the future will feel like." the possibility of expanded physical and intellectual horizons.

And above all it revels in the possibility of change. Serious science fiction takes science seriously, and its games provide a way of looking at the subjective implications of newly revealed objective truths of the Universe. Science fiction does not tell us what the future will bring, but at its best it helps us to understand what the future will feel like, and how we might feel when one way of looking at the world is overtaken by another.

To be sure, science fiction doesn't always connect in this way. It can be tired and cliché-ridden; the games it plays can be tedious, solipsistic power fantasies. And over recent years many of its finest practitioners have become so besotted by the endless new games that ever-accelerating progress allows them to play that their works can be inaccessible to the general reader. To demand that everything be accessible is to demand mediocrity - there is a role for dialogues that can be appreciated only by cognoscenti. But we believe that science fiction written for every scientist can be rewarding, too, which is why this issue sees the return of our popular showcase for short sciencefiction stories, Futures (see page 104).

Science takes place in a cultural context. The many forward-looking, ever-changing worlds of science fiction provide one that is both fruitful and enjoyable.

\section{Enough talk already}

\section{Governments should act on researchers' attempts to engage the public over nanotechnology.}

\section{T} here hasn't been anything quite like it in the history of science. Over the past three years, in Europe, the United States and Australasia, a plethora of groups of scientists and other citizens have discussed nanotechnology in extended exercises in 'public engagement. These initiatives have arisen partly because of the acute awareness by many that all is not as it should be either in the degree of trust in science and technologies on the part of the public, or in confidence in nanotechnology in particular.

As documented in a report published last week (see www.involve. org.uk/negreport), these initiatives have a number of common features. Definitions of the word 'nanotechnology' have been chewed over, optimism expressed that nanotechnology can benefit mankind, but - most importantly - concerns have been expressed about a lack of knowledge and regulation surrounding the impact of nanoparticles on health and the environment.

Equally notable were common outcomes for participants, where members of the public and scientists reported how much they had unexpectedly gained in understanding each others' perspectives. 